\title{
Revisibilidad de las resoluciones sobre personal
}

I. La Ley de I8 de marzo de 1944, que restableció la vigencia de la orgánica de la jurisdicción contencioso administrativa, introdujo modificaciones de honda trascendencia en el sistema de la justicia administrativa sobre personal, instaurando para ella un régimen especial y diverso.

Especial, por cuanto se prescribió el nuevo procedimiento del recurso de agravios frente a los actos de la Administración Central ; procedimiento de significado y alcance distintos a la preexistente competencia de la Sala de lo contencioso administrativo del Tribunal Supremo (I). Diverso, puesto que respecto a las resoluciones de la Administración local, sobre la misma materia, dejó subsistentes las facultades de enjuiciamiento de los Tribunales Provinciales de lo contencioso administrativo (2).

En definitiva, supone, en este punto, la Ley de 18 de marzo de I944, una rectificación del criterio dominante en la legislación administrativa española de los últimos lustros, toda vez que sustrajo un voluminoso núcleo de cuestiones a la órbita de la revisión jurisdiccional de la acción administrativa (3), sustituyendo la juris-

(1) Artículo $3 .^{\circ}$ do la Ley de 18 de marzo de 1944. Sin embargo, sobre los acuerdos que impusieren separac ón del Cuerpo o del servicio, de funcionarios inamovibles según Ley, quedó mantenida la jurisdicción revisora del Tribunal Supremo.

(2) Artículo $7 .^{\circ}$ de la Ley.

(3) Tras la Constitución de 1869 -escribe Alfaro-, sus principios expansivos sirvieron de fundamento a la confección de la Ley orgánica de los Tribunales y de otras disposiciones administrativas, y, en su consecuencia, el recurso contencioso administrativo se hizo extensivo a casi todas las cuestiones que rozaban con el nombramiento y separación de los empleados públicos. (Alfaro, Lo Ciontencioso administrativo, Madrid, 1881, pág. 31). 
dicción contenciosa por otra más adecuada de orden administrativo en los litigios relativos al personal (4); sustitución que, según :nterpretación auténtica, se da para aliviar a la primera de un enojoso volumen de asuntos poco trascendentes y atribuibles más bien a errores de la Administración que a verdaderas conculcaciones de derecho (5).

La estimación de los recursos de agravios compete al Consejo de Ministros, previo el necesario informe del de Estado en su Comisión Permanente (6), habiéndose creado, por Decreto de 4 de julio de I946, la Sección séptima en dicho Consejo a los exclusivos fines del indicado dictamen (7).

Trámite previo inexcusable del recurso de agravios es el haberse interpuesto y denegado el de reposición ante la Autoridad que dictó la resolución reclamada (8). La misma Ley -en los párrafos tercero y cuarto del artículo $40^{\circ}$ - y ulteriores disposiciones, han establecido los pormenores de ámbito, tramitación y fundamentación de esta nueva vía revisora de las resoluciones administrativas (9).

Pero la Ley de 18 de marzo de 1944, sin perjuicio de mantener

(4) De la Exprosición de Motivos de la Ley.

(5) Idem, id.

(6) Artículo 4. ${ }^{\circ}$ dé la Ley de 18 de marzo de 1944; artículo 17 de la de 25 de noviembre de 1944, orgánica del Consejo de Estado, y artículos 5.०, 49 y 169 del Reglamento de esta última, de 13 de abril de 1945.

(7) De conformidad con lo previsto en el articulo $7 .^{\circ}$ de la vigente Ley orgánica de dicho Consejo, y disposición adicional primera de su Reglamento de ejecución.

(8) Artículo 4..$^{\circ}$ párrafo $2 .^{\circ}$ de la Ley. A este respecto tiene declarado la jurisprudencia de agravios, que este recurso, por su carácter extraord nario, exige haber agotado antes en sus diversos grados las reclamaciones ordinarias en vía gubernativa, por lo que la reposición ha de interponerse frente al acuerdo del último superior jerárquico que esté llamado a resolver cuando la alzada sea procєdente. (Entre muchas, véanse Ordenes de 21 de noviembre de 1945, 18 de enero de 1946, 7 de marzo de 1947 y 13 de enero de 1948.) La dicción de este artículo nc fué, sin duda, lo suficientemente expresiva para evitar los errores de los no iniciados sobre la naturaleza y carácter del recurso de reposic:ón.

(9) V. VILlar y Romero, Los recursos de agravios en el derecho español, en Revista General de Legislación y Jurisprudencian, 1948, pág. 131 y sies., y Derecho Procesal Administrativo, 2. a edición. Madrid, 1948, pág. 1.54 y siguientes. Zarzaleíos, El recurso de agravios, Madrid, 1949. 
la competencia de los Tribunales Provinciales de lo contencioso administrativo para el conocimiento de los asuntos de personal, dentro de las atribuciones a los mismos señaladas en la Ley y Regiamento orgánicos de la jurisdicción (Io), establece la inapelabilidad de las sentencias por ellos pronunciadas en dicha materia (i I). Tales sentencias sólo son apelables mediante el recurso extraordinario regulado por Decreto-Ley de 8 de mayo de I93I.

Dicho recurso fué instituído para aquellos supuestos en los que, a virtud de lo establecido por el propio Decreto-Ley, no se diese la apelación ordinaria de los failos de los referidos Tribunales Provinciales, en razón de ser su cuantía inferior a veinte mil pesetas. Por él puede el Fiscal, en el plazo de tres meses y previa consulta a la Fiscalía del Tribunal Supremo, promover el conocimiento $\mathrm{y}$ revisión ante éste, constituída plenariamente la correspondiente. Sala, de las sentencias que, hallándose en el supuesto indicado, se estime sustentadoras de doctrina gravemente dañosa y errónea, habiendo de ser formulado en analogía con el recurso de casación, que en beneficio de la doctrina legal establece la Ley de Enjuicia-

En orden al ámbito temporal del recurso -que alcanza sólo a los actos admin:strativos posteriores a la fecha de la Ley- véase la Orden de 3 de julio de 1944. Sobre la comprensión en la materia de personal de las cuestionés relativas a 13 s. clases pasivas, la de 31 de octubre de 1947 . Sobre tramitación, las de 13 de junio de 1944,12 de abril de 1945 y la de 28 de enero de 1948 , en cuanto determina que el recurso previo de reposición, en los casos de clases pasivas, se interpondrá ante el Tribunal Económico Administrativo Central en las reclamaciones do clases pasivas civiles, y ante el Consejo Supremo de Justicia Militar en las de clases pasivas militares. La Orden de 25 de enero de 1949 da también normas de procedimiento, estableciendo la posible audiencia de los presuntos interesados.

Es curioso señalar, al respecto de la inclusión de la materia relativa a clases pasivas en la esfera revisora del recurso de agravios, el razonamiento de Laferriere que consideraba que una vez que la jubilac:ón se produce y cesa con ella la relación jurídico pública de empleo, los actos que se originan para regular los derechos y obligaciones, de tal índole pasiva, del funcionario y del Estado, no son actos de potencia pública, sino de gestión, deb:endo, por tanto, ser atribuído su conocimiento a los Tribunales ordinarios. (Laferriere, Traité de la juridictión administraive et des recours contentieux, 2.a edición, 1896, vol. II, pág. 203.)

(10) Artículos 11 y 22, respectivamente.

(11) Y también en cualquier otra de carácter municipal cuya cuantía no rebase la; veinte mil pèsetas. (Artículo $7 .^{\circ}$ de la Ley, que derogó en este punto el 223 da la vigente Mun:cipal de 31 de octubre de 1935.) 
miento Civil. La motivación de dicho recurso extraordinario de apelación, háa de ser fundada, por tanto, de conformidad con lo prevenido en el artículo 1.692 de nuestra Ley de Procedimientos Civiles.

Las decisiones del Tribunal Supremo en estos casos son intrascendentes a los efectos de la situación jurídica creada con motivo de la sentencia recurrida, limitándose a sentar doctrina, cuya inobservancia futura podría ocasionar responsabilidades para los tribunales inferiores.

Resulta, pues, que los actos administrativos en materia de personal están sometidos a procedimientos diversos de revisión según se trate de acuerdos de la Administración Central o Local. Para los primeros impera el sistema expuesto del recurso de agravios, que ha de decidir el Consejo de Ministros, esto es, un régimen puramente gubernativo; mientras que para los segundos subsiste, pero en única instancia, la jurisdicción de los Tribunales Provinciales de lo contencioso administrativo.

II. La primera consideración que este dualismo de sistema ha de plantear, es analizar el por qué del mismo y la estimación de las razones que en su favor se hayan alegado.

El preámbulo de la Ley se expresa a este respecto como hemos visto: sustituyendo... la jurisdicción contenciosa por otra más adecuada de orden administrativo en los litigios relativos al persona!, se alivia a aquélla de un enojoso volumen de asuntos poco trascendentes y atribuibles más bien a errores de la Administración que a verdaderas conculcaciones de derecho.

Parece, pues, que han influído fundamentalmente consideraciones de doble índole: de buena administración, encaminadas a aligerar el peso de los asuntos contencioso administrativos encomendados al Tribunal Supremo; $y$, también, el estimar que en este género de materias las cuestiones litigiosas entrañan mayormente errores administrativos que lesiones de derechos.

En consideración también a principios de buena administración, y en ejercicio de sana y honesta.crítica, que podrá ser equivocada, pero, en modo alguno, juzgamos perniciosa -y así lo tienen de- 
clarado las más altas dignidades de los poderes públicos (12)-, no estimamos afortunada, en el terreno de los principios, la solución que a estos problemas se dió por la Ley de is de marzo de 1944:

Veamos. Sabido es que en un buen ordenamiento jurídico no se debe vincular a consideraciones meramente prácticas la distribución de competencias, sino que aquélla ha de efectuarse primordialmente en armonía con la naturaleza de la función a realizar. Y si implícitamente, por dos veces, es expresado en la aludida Ley que las controversias de derecho deben ser resueltas por procedimientos y organismos jurisdiccionales —en el aludido párrafo de su preámbulo y en el artículo $30^{\circ}$-, no creemos que tal litigiosidad, en materia de personal de la Administración Central, sólo pueda presentarse en los casos de separación del Cuerpo o del servicio.

Si es lo cierto que buena parte de la relación jurídica de empleo público tiene matiz reglamentario, que pugna con la existencia de verdaderos derechos subjetivos en tales puntos, no lo es menos qu: aquellos derechos presentan una extensión indudablemente superior a la que en este caso, indirectamente, parece reconocérsele. Lor prueba la tradicional resolución en el contencioso administrativo de innumerables cuestiones a ellos referentes, bajo el imperio de un ordenamiento que exigía necesariamente la lesión de un dereche anteriormente establecido por una Ley, un Reglamento u otro precepto administrativo.

Para mantener los exactos límites que del espíritu conjunto de nuestra reglamentación jurídica deben derivarse, bastaba con iạ exclusión de las materias de discrecional incumbencia administrativa.

Que las lesiones de derecho puedan producirse por error de la Administración, en forma alguna justifica que en tales casos st: prive a los titulares de aquéllos de las garantías jurisdiccionales. que el Derecho patrio consagra en términos generales; ni mucho. menos todavía el que tales lesiones tengan una mayor o menor monta, cuestión de valoración puramente subjetiva, y què es del todo

(12) Véase el discurso del Excmo. Sr. Ministro de Educación Nacional, en el acto solemne de la apertura del curso académico 1949-1950, en la Universidad. dc Oviedo. 
inoperante en orden al sistema de seguridad y defensa jurídicas, que debe proteger los derechos hecha abstracción de su entidad cuantitativa.

Desde otros puntos de vista, tampoco nos parece aconsejable la atribución al Consejo de Ministros de la facultad de resolver, mediante los recursos de agravios, de los expedientes de esta índole, ya que, en el actual ritmo de la vida administrativa de los Estados, la ingente tarea que sobre aquél pesa no se compadece con los fines de mejor distribución de asuntos que en el preámbulo de la Ley se indican.

$\mathrm{Y}$ puesto que la competencia de un organismo más político que otra cosa, y a lo sumo administrativo, como es el Consejo de Ministros - prescindamos ya de consideraciones sobre el problema de justicia administrativa retenida-, en rigor de principios sobre atribuciones de competencias no debe alcanzar sino a cuestiones de dicha índole política y administrativa, pero no a juzgar sobre ia base de aplicación estricta de criterios jurídicos, cual es nota esencialísima del recurso de agravios - recurso de legalidad.

Como muy bien señalara Rovelli, el carácter contencioso de una determinada cuestión administrativa se manifiesta cuando en su resolución no pueden acogerse motivos administrativos, discrecionales, por tanto, en su apreciación, sino motivos jurídicos, de legalidad; pues sobre éstos puede haber controversia 0 contienda, pero no sobre aquéllos (13).

Siendo evidente que el recurso de agravios es de la especie últimamente descrita, la lógica, y siempre dentro de la inspiración del sistema, hubiera impuesto haber atribuído plenamente la facultad de decisión al Consejo de Estado, bajo un régimen de justicia administrativa delegada. Lo contrario no parece defendible ni siquiera por las razones de rapidez que a veces se indican, dado lo dicho en orden al cúmulo de asuntos que al Consejo de Ministros compete y la existencia de esa Sección especial de recursos ein el de Estado.

(13) V. Rovelli, Usservazioni sulla natura del giudizio dinanzi al Consiglio di Stato, Scritti Giuridici in onore di Santi Romano, 1940, vol. II, págs. 323 y ss. 
Lo dicho no quiere indicar que podamos sentir especiales reparos en lo relativo a la forma de orientarse este sistema de justicia administrativa, cuya efectividad, bien probado resulta de las experiencias de los distintos países, no se ha de hacer depender de su atribución orgánica, sino de la rectitud con que se ejerza; simplemente nos cuidamos de señalar la falta de justificación científica, en nuestro sentir, para este duaiismo de regímenes al respecto de la revisión de las. cuestiones de personal, según se trate de la Administración Central o Local.

Y ello, además, por cuanto las restantes declaraciones del preámbulo de la Ley no autorizan a pensar que el caso puedia tener motivaciones análogas a las que indujeron a retrasar el res. tablecimiento de lo contencioso administrativo del Estado en relación al de las entidades provinciales y municipales, pues suficientemente claro queda dicho en aquellas que se quiere restaurar, con todas sus consecuencias, la jurisdicción contencioso administrativa en la esfera de la Administración. Central (14).

La exclusión de la misma de los actos motivados por razones puramente gubernativas, y la causa que el artículo $50^{\circ}$ de la Ley de 18 de marzo de 1944 añadió a las del 84 de la de 22 de junio

(14) aLas circunstancias excepcionales en que se hallaba el Poder público durante nuestra Guerra de Liberación, y la necesidad imperiosa de mantener bajo u 1 mismo fuero la plenitud de poderes aconsejaron la limitación del derecho a revisar determinadas actividades administrativas, suspendiendo el funcionamiento de la jurisdicción contencioso administrativa, tal como fué regulada por la Ley d.? 1894 y sus posterıores modificaciones. En su virtud, la Ley de 27 de agosto de 1938, reorganizando el Ti:bunal Supremo, estimó que la jurisdicción de la Sala tercera debía limitarse a los recursos promovidos contra las resoluciones de los Tribunales Provinciales, si bien el Decreto de 2 de marzo de 1939 abría un cauce más amplio a la juísdicc:ón contenciosa, extendiendo la competencia de la expresada Sala a los recursos contra acuerdos de la Administración Central de fecha anterior al 18 de julio de 1936. Definida ya con firme y vigorosa traza la personalidad del Estado, llega la hora de situar la v'da juridica de España en la cumbre He su plenitud esplendorosa, como fué norma maestra de su gran historia imperial. Por ello se abre de nuevo el recurso contencioso administrativo para todas aquellas disposiciones posteriores a la fecha de la publicación de esta Ley, con las garantías indispensables para. su más amplio ejercicio, sin olv:do de las prerrogativas del Estado en asuntos dé gravedad excepcional.» (De la Exposición de Motivos de la Ley de 18 de marzo de 1944.) 
de 1894, en orden a la facultad de suspensión o inejecución de las sentencias, encierran, en nuestra opinión, garantías suficientes para los poderse públicos respecto a los problemas circunstanciales que las aludidas cuestiones de personal-pudieran plantear.

Finalmente, el que en la esfera de las Corporaciones locales, los Tribunales Provinciales de lo contencioso administrativo sigan siendo competentes para el conocimiento de estos litigios, está a las claras indicando que no existe razón de fondo que aconseje el otro criterio en el ámbito de la Administración del Estado, habida cuenta del extraordinario volumen de importancia que en los aspectos político y administrativo presenta el desarrollo de la vida local, y las líneas cardinales de nuestro ordenamiento, por razón de las cuales la acción estatal no sufre solución de continuidad desde los superiores a los inferiores grados de la organización administrativa.

Independientemente y aun sobre las señaladas objeciones teóricas, cabe pensar en la posible superación de los inconvenientes doctrinales por la realidad de las cosas, por cuanto en la reg!r:mentación del recurso de agravios puede hallarse el germen de un: jurisprudencia seriamente producida y elaborada con criterio flexible y hasta innovador, que en cierta medida ya apunta en las resoluciones sobre tales recursos.

III. Entrando en otro género de consideraciones, hemos de analizar cómo el recurso de agravios tiene la importancia trascendental de haber introducido en la órbita de la Administración del Estado esa añorada revisión objetiva de los actos administrativos: bien que limitada, claro es, a la especie concreta en que rige.

Como es sabido, dice la Ley que el recurso de agravios ante ef Consejo de Ministros sólo podrá fundarse en vicio de forma o infracción expresa de una Ley, un Reglamento u otro precepto administrativo (I5), motivos todos que suponen el fin de defensa y garantía de la legalidad que caracteriza el aspecto objetivo de la justicia administrativa.

La trascendencia del hecho fué certeramente percibida, y mati-

(15) Artículo $4 .^{\circ}$, párrafo $4 .^{\circ}$. 
zadas profundamente sus posibles últimas consecuencias, por e! maestro Gascón y Marín cuando escribiera: "La promulgación de la nueva Ley constituye evidentemente una intensificación del régimen jurídico estatal, del Estado de Derecho, que tanto se admite, como se hizo en el siglo $x{ }^{\prime x}$, en sentido subjetivo, o cual Estado de Derecho objetivo, como es característica de los nuevos regímenes políticos, en el que se proteja la situación reconocida a los particulares en interés de la comunidad política, supone la afirmación del principio de legalidad como norma de actuación de los servicios públicos, como principio básico de la actividad decisoria de las actividades administrativas y como interés supremo del Estado, de que las leyes y disposiciones legales generales dictadas por los órganos competentes tengan siempre la conveniente efectividad al ser aplicadas en casos concretos") (16).

Esas posibles últimas consecuencias a que queda hecha alusión. y a las que realmente no se ha llegado pese a algunas afirmaciones en contrario, podían haber sido de doble y distinto signo. De un lado, la proclamación de la tesis de que la existencia de una revisión de legalidad implica la posibilidad de promoverla por parte de cualquier ciudadano. En una palabra, a estimar que la jurisdicción o revisión objetiva, a falta de texto que la constriña, supone una vía de acción popular. También equivale ello, desde distinto aunque muy afin punto de vista, a revivir viejas teorías afirmadoras de que la mera promulgación de cualquier norma de derecho objetivo hace nacer el derecho público subjetivo de los particulares al cumplimiento de esa norma (17).

(16) GaScón y MaRfN, Restablecimiento del recurso contencioso administrativo, e.1 Revista de Estudios de La Vida Local, 1944, pág. 274.

(17) Es sobre todo la extensión de la idea del derecho público subjetivo del administrado a la legalidad administrativa -escribe Bonnard-, lo que parece habe: hallado mayores resistencias. La idea del derecho público subjetivo del administrado no debe estar limitada en un Estado de Derecho a obligaciones de carácter individual incumbentes a la Administración. Es preciso admitir el derecho subjetivo siempre que se cumplen sus condiciones de existencia. Así es preciso extenderla a toda s:tuación que supone para la Administración una obligación establecidá en interés de los administrados; $y$, particularmente, cuando existe para ella obligación a una determinada legalidad en la realización de sus actos jurídi- 
Pero desde este aspecto extensivo del recurso no se plantearon las dudas de los autores, aunque es notorio que no conteniendo la Ley previsión alguna a este fin, quedaba latente la cuestión. Cues. tión que ha sido resuelta por la jurisprudencia de agravios, al proclamar en diversas resoluciones la necesidad, exigida con criterio rigorista, de ser parte interesada para tener aptitud a la promoción del recurso ; no siéndolo incluso quienes estando directamente afectados por la cuestión de fondo no fueron parte en los trámites previos a la iniciación de la vía de agravios, o en los procedimientos que en fechas anteriores eran procedentes y de los que trae causa el problema planteado (18).

Más explícitamente, se ha declarado en recientes resoluciones que hay personalidad en el recurrente para impugnar disposición que afecta directamente a la situación en que se halla (19), pues la personalidad para recurrir en agravios no deriva de ser funcionario público, sino de ostentar un interés individual, directo y legi-

cos, es preciso reconocer en favor del administrado un derecho a la legalidad administrat:va.

Los autores clásicos del Derecho administrativo francés defendieron esta extensión de los derechös públicos subjetivos. El que la legalidad sea sólo un interés de? administrado -doctrina dominante- no se ha mantenido siempre. Bajo el Segundo Imperio se sostenía el derecho a la legalidad. Foucart (Eléments de droit public et administratif, $4{ }^{\text {a }}$ edición, tomo I, págs. 204 y sigs.; III, págs. 658 y sigs), Serrigny (Traité de la compétence et de la procédure en matiére contentieuse-administrative, $4{ }^{\text {a }}$ edición, 1865, tomo I, págs. 47 y sigs.) y Laferriere (Traité de la juridiction administrative et des recours contentieux, tomo II, pág. 436) la defendieron. El punto de vista de estos autores era que desde el momento en que hay obligación do la Administración establecida en interés del administrado, existe un derecho para éste; incluso cuando esta obligación no roza sino con la legalidad del acto. Sólo cuando la Administración está investida de un poder discrecional, es cuando el admin:strado no puede invocar frente a la Administración sino un interés. (V. Bonnard, Précis de Droit Administratif, Préface a la 3.a edición, er. la 4.a, 1943, págs. 11-13.)

(18) Así es el caso del recurso formulado frente a la orden que acordó la ejecución de una sentència de la Sala de lo contencioso administrativo del Tribunal Supremo, cön respecto a aquellos que no siguieron la vía contenciosa en su día. (V. Ordenes de resolución de recursos, de 19 de mayo, 9 y 30 de junio de 1948 , a Boletines Oficiales de 5, 8 y 18 de agosto de 1948, respectivamente.)

(19) Orden de 8 de iseptiembre de 1949, aBoletín Oficial del 25 del mismo mes $y$ año. 
timo en una resolución administrativa dictada en materia de personal (20).

Inspirándose en la doctrina expresada, se ha resuelto que los Secretarios no incluídos en la terna propuesta por el Tribunal calificador, pueden recurrir en agravios para la revisión de las calificaciones de méritos llevadas a cabo por el Tribunal; suponiendo el recurso no un nuevo examen comparativo de méritos, que es de exclusiva competencia del Tribunal, sino sólo la revisión de los criterios por éste utilizados en la selección de dichos méritos, y ver si se han infringido en ellos las normas establecidas (2 I).

A este respecto de legitimación subjetiva es de interés la declaración de que el Presidente de una Audiencia Provincial carece de facultades para interponer, en concepto de tal, recurso de agravios contra resoluciones que lesionan presuntos derechos de los Magistrados y Fiscales adscritos a ella, arrogándose su representación (22), por cuanto la Audiencia Provincial, ni por su carácter de órgano del Estado, ni por los fines que las disposiciones vigentes le atribuyen, es entidad creada para asumir la defensa de los intereses profesionales o de grupo, a los efectos de formular una reclamación en nombre de los interesados.

Pero ha sido el aspecto restrictivo del carácter objetivo del rocurso de agravios, el que ha merecido hasta ahora el interés de los autores que de aquél se han ocupado. En efecto, se ha dicho $-\sin$ duda bajo la influencia de la dicción del párrafo $4 .^{\circ}$ del artículo $4 .^{\circ}$ de la Ley- que el recurso de agravios no es ya que sea objetivo. sino que es exclusivamente objetivo (23).

Se sostiene que dicho recurso no puede fundarse propiamente en motivos subjetivos de infracción de un derecho préestablecido

(20) Orden de 22 de septiembre de 1949, aBoletin Oficialo del 2 de octubre del mismo año.

(21) Orden de 25 de junio de 1948, aBoletín Oficials de 14 de agosto del rnismo año.

(22) Orden de 3 de diciembre de 1948, aBoletín Oficial del 12 del mismo mes y año.

(23) V. Villar y Romero, y Zarzalejos, obs. cits. 
a favor del recurrente, si bien se añade que en el fondo la infracción objetiva produciría siempre la subjetiva (24).

Frente a uno y otro punto de vista hemos de mostrar nuestra disconformidad. Respecto al segundo -cuando se afirma que la infracción objetiva producirá siempre la subjetiva-, porque, como más atrás queda escrito (25), es doctrina imperante en el Derecho público moderno que de las normas objetivas no derivan necesarizmente derechos subjetivos individuales. Opinión a la que sólo se sustrae la corriente doctrinal que, al negar la existencia de los derechos subjetivos, $\mathrm{y}$, por tanto, de los públicos de la misma índole, afirma, a sensu contrario, que de admitirse aquéllos habrá de sostenerse en todo caso su derivación necesaria de cualquier norma jurídica, existiendo, por ende, siempre, un derecho público subjetivo al cumplimiento de la legalidad.

Pero tal forma de entender este problema no tiene privanza alguna, ya que, derecho objetivo, legalidad y derecho público suijetivo, tienen dos esferas delimitativas no necesariamente convergentes. El respeto a la legalidad establecida ha de darse con independencia del interés individual específicamente tutelado que justifique la existencia de un derecho público subjetivo (26).

Es este un caso manifiesto de aquellos en los cuales la trasläción de los principios de derecho privado a la esfera del público se opera sin completa correlatividad, pues son distintas las bases sobre que reposa el ordenamiento general, y distintos los fines que se persiguen con la norma, como nos demuestra la abundante bibliografía sobre el problema de los derechos públicos subjetivos.

Esa necesaria subjetivación de la infracción de la norma objetiva, sólo se produce con respecto a uno de los elementos de la relación jurídico-pública : con respecto al Estado, o entidades que con análogo carácter soberano en ella intervienen, por cuanto en

(24) VILlar y Romero, Los recursos de agravios en el Derecho español, en -Revista General de Leg:slación y Jurisprudencia», 1948, pág. 140. Rat fica su afirmac:ón, cuando también escribe que la infracción subjetiva no puede ser ni el motivo ni la base para que el recurso prospere. (Derecluo Procesal Adminzsiontz2*0, 2.a edición, pág. 155.)

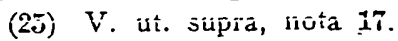

(26) V. Hauriou, Aux Sources de Droit. Le Pouvoir, l'ordre et la liberté, en *Cah:er de la Nouvelle Journèe, núm. 23. 
uno u otras se da la única posible subjetivación de los intereses colectivos in genere. Con acierto escribió Sarwey (27), que aunque no exista un derecho particular lesionado, si se ha inferido un agravio al orden jurídico general existe un derecho subjetivo que también recibe en sí la injuria: ese derecho es del Estado, que poses un específico interés en que no se perturbe su vida ordenada. El interés particular se concibe aquí no especificado ni concretado, y en buenos principios insuficiente para servir de base a un derecho público subjetivo (28).

Más todavía interesa el otro punto de discrepancia, a que nos hemos referido, con la tesis anotada. Se dice que el recurso die agravios es exclusivamente objetivo, y que no es motivo para su fundamentaciỏn la simple lesión de un derecho subjetivo anteriormente preestablecido; que sólo las causas señaladas y taxativamente objetivas abren la puerta de esta vía revisora.

Con independencia de que, como más adelante veremos, la propia jurisprudencia de agravios haya sostenido opinión contraria al parecer expuesto, es indudable que para que tal parecer h1biera sido defendible habría resultado preciso la consagración de un principio al que, afortunadamente, no se ha llegado entre nosotros: la sustitución de la noción derecho público subjetivo por la de situación jurídica subjetiva (29) —como fué sistema propio del derecho público del nacional socialismo alemán (30)-; expresión culminante del más peligroso de los individualismos, el individua-

(27) SARWEY, Das öffentliche Recht und die Verwaltungsrechtsplege, 1880, página 69

(2S) En nụestra opin:ón existe un so'o matiz de esta cuestión en que, por aplicación del Derecho natural al principio de fundamentación de los derechos públicos subjetivos, debe llegarse a la solución contraria; pero este punto, de bases ampliamente especulativas, trasciende con mucho de la consideración presente.

(29) Así lo hace Vacchelli, La difesa giurisdizionale dei diritti dei cittadini verso l'autoritá amministrativa, en Orlando, aPrimo Trattaton, vol. III, páginas 248-249.

(30) V. Royo Villanova, S., Lo contencioso adminisiraivo en los Estados total:tarios, en «Revista General de Legislación y Jurisprudencian, 1941, págs. 307 y sigs., y GARcfa OVIEDo, Consideraciones acerca del recurso contencioso administrativo en el Estado totalitario, en aRevista de la Facultad de Derecho de la Universidad de Madridn, págs. 72 y sigs. 
lismo del todo, que no conoce ni valora otro término de la relación, con propia estimativa, que a sí mismo.

Antes decimos que el maestro Gascón y Marín había matizado muy certeramente, cuando nos hablaba en el párrafo transcrito del Estado de Derecho objetivo, las últimas consecuencias del sistema que se instauraba. Esas últimas consecuencias hubieran sido, en efecto, el encerrarse el ámbito del recurso de agravios en un carácter estrictamente objetivo. Mas, según decimos, esa consecuencia precisaba de la referida eliminación del valor derecho público subjetivo. Eliminación que sería atrevido y arbitrario dar por realizada en nuestro ordenamiento jurídico, siendo así que ia misma Ley de 18 de marzo de 1944 restauraba el contencioso administrativo Central por lesión de derecho subjetivo. Eliminación además, que no se compadece con la inspiración general del Derecho público en vigor y menos con las palmarias declaraciones del Fuero de los Españoles.

Podría pensarse que tal eliminación, si no explícita e inequfvocamente formulada en un texto general, iba implícita en la sustracción al contencioso administrativo de todas las cuestiones atribuídas a la competencia del recurso de agravios; eliminación, por tanto, parcial. Esta es sin duda la justificación de las opiniones reseñadas; pero, sin embargo, contra ella se alza el propio criterio de la jurisprudencia de agravios.

En efecto, dicha jurisprudencia ha admitido la fundamentación del recurso en la alegación de derechos subjetivos de desconocidos - lesionados, hecha hipotética abstracción de la alegación y existencia de infracción de un precepto legal. Así, según resolución de 29 de enero de 1949 (31), la via de agravios no es competent. respecto a derechos o preferencias que puedan asistir, mientras no se pongan en relación con acto administrativo que venga a desconocerlos. En otras ocasiones, se ha declarado, como base de desestimación del recurso, el que el recurrente no cita derecho alguno que pueda estimarse desconocido o lesionado (32), o que carece de tal derecho (33).

(31) aBoletin Oficials de 17 de febrero del mismo año.

(32) Orden de 15 de junio de 1949, «Boletín Oficialn de 10 de julio.

(B3) Orden de 30 de septiembre de 1949, aBoletín Oficials de 14 de oc'ubre. 
Más explícitamente se ha dicho en otros casos: si se lesiono algún derecho del que fuera titular el recurrente, $y$, en consecuencia, si se creó la situaoión de agravio, inexcusable base del recurso (34). O lo que todavía es más contundente: Considerando que el recurso de agravios exige como requisito ineludible de fondo, como de su propia denominación se desprende, la existencia de. un agravio, entendiendo por tal la real o presunta lesión por la disposición de que se recurre de un legitimo interés o derecho establecido a favor del recurrente por una Ley, Reglamento u otri precepto administrativo, no siendo por ello título bastante para recurrir el de mero ciudadano que juzgue una disposición como contradictoria de otras y derechos reconocidós por ésta, sino que se precisa la alegación concreta de los derechos subjetivos del recurrente que se estimen violados (35).

$\mathrm{Y}$ es que realmente, y salvo que se haya hecho esa supresion legislativa de los derechos públicos subjetivos, a que anteriorment: nos referimos, de que una vía de revisión de actos administrativos lo sea de carácter objetivo, no puede inferirse que lo sea propia y exclusivamente ni de derecho objetivo ni subjetivo, pues lo único evidente que de ella resulta es que está preordenada a la defensa de los simples intereses de índole subjetiva, y no ya únicamente de los derechos de tal índole (36).

Bien se puede decir en este caso, en consecuencia, y a salvo de una declaración específica en contrario, que lo más comprende lo menos, y que, por tanto, si la revisión objetiva contempla la defensa de los simples intereses subjetivos que no han concretado específicamente en un derecho de tal naturaleza $-\mathrm{y}$ que obtienen su protección sólo a través de la tutela de la legalidad constituí$\mathrm{da}-$, en ella se ha de comprender, a mayor abundamiento, la defensa de los derechos subjetivos, que suponen una más perfecta

(34) Idem, id.

(35) Orden de 6 de octubre de 1949, aBoletín Oficials del 17. del mismo mes; y la de 2 de julio del mismo año ( $a$ B. O.» del 6 de agosto), en la que se expresa que. el recurso de agravios ha de esta- fundado si no en la lesion de un derecho subjetivo al menos en la defensa de un interés personal, directo y legítimo.

(36) V. Rovelli, Osservazioni sulla natura del giudizio dinanzi al Consiglio di Stato, en Scritti Giuridici in onore di Santi Romano, 1940, vol. II, páginas 335 y sigs. 
expresión de los intereses de tal especie. Lo que sí caracteriza al sistema es la contemplación inmediata no de la reintegración del interés lesionado, sino de la anulación del acto causa de la lesión. Por eso se dice objetiva, porque desde este plano de consideración opera sobre la infracción alegada.

En conclusión, que si no es exacto suponer que cualquier infracción del derecho objetivo lleve consigo necesariamente la lesión o desconocimiento de un derecho subjetivo; sí puede decirse que para alegar y promover una revisión de legalidad es motivo suficiente la alegación de haberse lesionado un derecho subjetivo, admitida que sea la noción de éste ; y por cuanto; además, dicha lesión lleva implícita la infracción de una Ley, Reglamento u otro precepto anterior en que dicho derecho se reconociera -ámbito jusnaturalista, en la esfera en que así lo concebimos, de la fundamentación de los derechos públicos subjetivos- o se constituyera -ámbito político o solidarista de tal concepto.

La tesis defendida tiene en nuestro ordenamiento jurídico administrativo una expresión clara y contundente : la del artículo 227 de la vigente Ley Municipal de 3 I de octubre de 1935, cuando pot él se permite que, sin haber sido formalmente interpuesto recurso de anulación en tiempo y forma, y sí únicamentè el de plena jurisdicción, el Tribunal Provincial de oficio, o a instancia del Fisca!, $\mathrm{y}$ en dicho artículo se suele fundar la alegación subsidiaria in vocc en la vista, dicte sentencia de anulación si existieren méritos para ello. Se estima, pues, bien claramente, que la alegación de lo más - la lesión de derecho subjetivo- puede servir de medio para promover el reconocimiento de lo menos -infracción de derecho objetivo.

La diferencia de principio de la tesis aquí propugnada con aquella de la que disentimos, estriba en que la primera implica la estimación de la revisión objetiva, como forma de hacer realidad que el sacrificio del interés subjetivo o individual, frente :! colectivo o general, no se produzca sino en los casos en que tal sacrificio haya sido consagrado como necesario en el ordenamiento jurídico. La contraria equivale a sostener, implícitamente, que il interés individual debe ceder en todo caso ante el colectivo, y que a aquél sólo se tutelará en la medida que a la vez suponga defensa 
o promoción del segundo. Supone también colocar en una situación precaria, y en ocasiones de desamparo, a los derechos subjetivos definitivamente adquiridos, por cuanto obliga a la carga de la prueba de la infracción de una norma, que puede incluso haber sido derogada, pero de cuya derogación no debe deducirse, si no se niega el valor de los derechos públicos subjetivos, la supresión de las situaciones definitivas en otro tiempo creadas a su amparo durante su vigencia.

La apreciación de este nuevo matiz de la cuestión, es un argumento final y decisivo respecto a la estimación de la naturaleza del recurso de agravios, que, pese a la dicción del artículo $4 .^{\circ}$ de la Ley, no puede calificarse de estrictamente objetivo, porque, desde los tiempos mismos de la iniciación de la jurisprudencia de agravios, tal jurisprudencia aplica e interpreta legislación ya derogada, cuando, por las circunstancias cronológicas del caso, debe ser aplicada para el reconocimiento de los derechos por ella consagrados y según ella definitivamente adquiridos. Si fuera como se quiere por los autores de referencia, ello no hubiera sido posible si había que atender únicamente a la legalidad constituída y no a la existencia de derechos que debían ser tutelados. Se aprecia bien la enorme trascendencia de sostener uno $u$ otro punto de vista, en el ámbito contractual de la relación jurídica de empleo, en el que cabé la existencia de tales situaciones definitivas de derecho adquirido.

Expuesto cuanto antecede, estamos en condiciones de reforzar nuestro punto de vista anterior, que mostraba las objeciones de tipo doctrinal a la reducción efectuada en el marco de la jurisdicción contencioso administrativa, llevando a la vía de agravios - víd gubernativa - cuestiones en las que verdaderamente se trata de una controversia sobre derechos, como se ha reconocido en las resolticiones citadas y con la expresivłdad que los párrafos transcritos manifiestan, pese a las declaraciónes de contrario contenidas en el preámbulo de la Ley de 18 de marzo de 1944.

Muy plausible, pues, hemos de juzgar la tendencia de establecer una revisión objetiva con respecto a las resoluciones de la Administración Central, incluso también acertada la modalidad de independizarla de las clásicas revisiones jurisdiccionales, pero la 
obra, para ser completa, hubiera exigido que no se produjera esa interferencia de fondo en que se ha caído. Que la vía de agravios hubiera sido, en verdad, exclusivamente objetiva como complementaria de la contencioso administrativa, y no sustitutiva de ella como con razón a los hechos se la considera. Que a lo contencioso administrativo hubiere seguido atribuído cuanto en la órbita de las cuestiones de personal es susceptible de producir derechos subjetivos, y a la revisión de agravios correspondiera tan sólo cuantus en aquélla no es idóneo para generar derechos públicos subjetivos, es una estricta vía de legalidad.

Ello requeriría declaraciones ostensibles a tales respectos, in lingar de expresiones tímidas que luego no han podido ser mantenidas en el efectivo funcionamiento del nuevo recurso, como era lógico que ocurriera dado que se operaba sobre bases inseguras, po: ser evidente que de nuestro ordenamiento jurídico derivan, en materia de personal, más derechos subjetivos que los que parecían únicamente consagrarse en el artículo $3 .^{\circ}$ de la Ley de 18 de marzo de I944.

Debe tenerse en cuenta, además, para que lo dicho resalte con mayor evidencia, que la configuración de las llamadas cuestiones de personal se ha efectuado con bastante amplitud de criterio, incluyendo en ella no únicamente las referentes a la relación jurídico pública de empleo, sino extensivamente todo "lo relativo a la selección, situaciones, derechos y deberes del personal que colabora o ha colaborado con la Administración en la prestación de serviciosi) (37). Así, se ha declarado ser materias de agravios las relativas al personal de las Secretarías de las Cámaras Oficiales de la Propiedad Urbana (38), a los médicos del Seguro de Enfermedad (39), a la colegiación profesional de los procuradores de. los tribunales, a las de los abogados (40), etc., etc.

(37) V. Ordenes de 22 de septiembre ( $\alpha$ B. O.» de 2 de octubre) y 14 de octubre ( $\alpha$ B. O.» de 22 del mismo mes) de 1949, y tamb:én las da 5 de febrero, 31 de marzo, 15 de junio y 13 de septiembre de 1948 ( $\alpha B B$. OO. de 29 de julio, 1 y $\boldsymbol{y}$ de agosto y 19 de septiembre).

(38) Orden citada de 22 de septiembre de 1949.

(39) Orden citada de 15 de junio de 1948.

(40) Orden citada de $\overline{5}$ de febzero de 1948; articuio 15 del Estatuto de la Abogacía de 28 de jun:o de 1946, y ar'ículo 7 del Esia'uio General de los Colegios de Abogados, de :" de febrico de 1947 . 
IV. De otro lado, según hemos visto, la Ley de 18 de marzo de 1944, al declarar inapelables los fallos de los Tribunales Provinciales de lo contencioso administrativo en materia de personal, consignó, como ya ha quedado indicado, la posibilidad de recurrur contra ellos a través de la apelación extraordinaria del referido Decreto-Ley de 8 de mayo de 1931 .

A primera vista surge en orden a estos casos una cuestiói trascendente. Es la relativa a saber si a tenor de la regulación restrictiva en dicho Decreto-Ley establecida para la promoción di: tales recursos, la misma sólo podrá ser realizada, como en él se dispone, por el Ministerio Fiscal. Los términos del artículo $7 .^{\circ} \mathrm{d}$ la Ley de 1944 no autorizan, en verdad, para deducir presunción alguna que no se ajuste a los exactos límites de aquél; y, sin embargo, si se quiere que el precepto haya de tener trascendencia efectiva, habrá de convenirse en la necesidad de dar al recurso una mayor extensión.

Los fallos en materia de personal de los Tribunales Provinciáles de lo contencioso, resuelven sobre asuntos de las Corporaciones locales con sus empleados, y en estos casos, como normalmente las dichas Corporaciones se personan en el pleito con su'Letrado y Procurador, el Fiscal hace uso de ordinario de la autorización que le confiere el artículo 24 de la Ley de 22 de junio de I894, absteniéndose, por tanto, de intervenir en el litigio. Tal abstención encuentra su razón de fondo en el carácter subsidiario con que se considera a su actuación en estos procesos, habida cuenta de los términos del artículo 23 de la susodicha Ley: "El Fiscal defenderá por escrito y de palabra a la Administración y a las Corporaciones que estuviesen bajo su especial inspección y tutela, mientras estas últimas no designen Letrado que las represente.)

A este respecto, la instrucción tercera de la Circular de la Fiscalía del Tribunal Supremo de 12 de enero de 1940, al complementar, en orden a los casos de recursos contenciosos de anulación interpuestos al amparo de la vigente Ley Municipal, lo dicho por otras anteriores circulares - de 27 de enero de 193 I y 9 de enero de 1935- establece que en los recursos de plena jurisdicción si los Ayuntamientos, que son los directamente interesados en los acuerdos municipales, se personan en el pleito de que se trate, no 
es necesaria la defensa por parte del Fiscal, ya que la propia Corporación que dictó el acuerdo acude a defenderlo ; pero, en cambio, en los recursos de anulación - añade - nada debe suponer tal defensa por parte del Ayuntamiento interesado, por ser la intervención del Fiscal por vía de informe y como defensor de la Ley.

Evidentemente, en consecuencia, que, a tenor de la citada Circular, la posición del Fiscal mientras es plenamente propia a siı peculiar misión de Ministerio Público, custodio del Derecho, en los recursos de anulación, lo es de mero defensor subsidiario en los de plena jurisdicción contra las Corporaciones Locales. Como tal, cuando la entidad directamente interesada acude en defensa de sus resoluciones, puede abstenerse; lo que equivale a reconocer que tal abstención es legítima porque el asunto controvertido no es del interés general de la Administración, como reza el aludido artículo 24 de la tantas veces mencionada Ley orgánica de la jurisdicción contencioso administrativa, que es el que se aduce en estos casos de abstención, y en el que la fundamenta la instrucción cuarta de la precitada Circular de la Fiscalía del Tribunal Supremo de 1940.

Si esto es así, bien se comprenderá la razón que nos asiste cuando sostenemos que para hacer eficiente la vía del recurso extraordinario de apelación contra las sentencias de los Tribunales Provinciales de lo Contencioso administrativo en materia de personai. es necesario dar al mismo una configuración más amplia de la que: actualmente tiene; ya que habiendo de ser promovido por el Fiscal, y por razón de estimar gravemente dañosa y errónea la doctrin't sentada por la sentencia recurrida, lógica e ideológicamente dificulta tales apelaciones la abstención de aquel Ministerio público.

No queremos decir que no puedan producirse, pues prescindiendo de si en dichos casos debe o no el Fiscal seguir siendo estimado como parte -a la negativa parece que se inclina López Rodó, at. decir que el Ayuntamiento es entonces parte única (4 4 )-, la facultad atribuída lo está en términos generales y de forma especialísima, con independencia de su actuación en el proceso. No puede haber por ello decaimiento en tal facultad, como concretamente-

(41) LÓPEz RODó, El coadyuvante en lo contencioso administrativo, pág. 61. 
prevé el párrafo segundo de la aludida instrucción tercera de 'a Circular de 12 de enero de 1940, que expresa que la abstención del Fiscal sólo puede referirse a la defensa de las Corporaciones y no a aquellas otras intervenciones, en esos mismos pleitos, en las que propiảmente no actúe en defensa de los Ayuntamientos, sino en cumplimiento de su deber de promover la acción de la justicia.

Sin embargo, piénsese en la incongruencia que supone que habiéndose abstenido el Fiscal en base a no ser el litigio de interés general para la Administración, más tarde, al recaer sentenciat en dicho asunto, sea ésta apelada en recurso extraordinario por el propio Fiscal, por estimarla sustentadora de doctrina gravemente dañosa y errónea. $\mathrm{Y}$ tanto más cuanto se tiene declarado que ia apelación por infracción de doctrina legal, en estos recursos que estamos considerando, ha de formularse contra la sostenida en :a parte dispositiva o fallo de la sentencia (42), es decir, en el punto concreto de la resolución del asunto sometido a enjuiciamiento y que fué catalogado por el Fiscal como de no interés general para la Administración.

Tal cual actualmente se halla regulado, este recurso extraordinario es un artificio prácticamente ocioso y meramente bizantino aplicado a las cuestiones de personal, pues a los inconvenientes que al recurso en sí señalara Martín Retortillo (43), ha de añadirse, en el caso que nos ocupa, la incongruencia que dejamos apuntada.

Como quiera que es lógico y razonable pensar que la inspiración de la Ley de 18 de marzo de 1944, al prescribir este recurso en el supuesto que consideramos, fué no dejar plenamente liberadas de todo control las sentencias de los Tribunales Provinciales de lo Contencioso en materia de personal, al objeto de poder establecer principios de unidad que eviten contradicciones en las dictadas por los diversos tribunales (44), debe reconocerse que, para hacer en

(42) Sentencia de 19 de octubre de 1946.

(43) Martín Retortillo, Notas sobre el procedimiento contencioso administrativo, Huesca, 1933, págs. 87 y sigs; Modificaciones en lo contencioso municipal, en. Revista de EStudios de la Vida Local, 1944, pág. 393

(44) Es interesante el siguiente. Considerando de la sentencia de 23 de febrero de 1948: QQue toda doctrina supone la enseñanza de conocimientos en determi- 
verdad real el logro de tal objetivo, convendría regular con criterio menos restrictivo que el actual la utilización del recurso en cuestión, mediante la supresión de las rigideces que atenazan su vida.

$Y$ esto tanto en el orden de la trascendencia de los fallos que en el mismo se originen -ya que por irrelevantes para la situación jurídica creada presentan un carácter platónico y trasnochado en el actual estadio de la vida del derecho-; cuanto respecto a las posibilidades de ejercicio por las Corporaciones y los particulares, o al menos por aquéllas ; como también reduciendo la inflexibilidad de su fundamentación, para asimilarlo en un todo a la casación civil con la que en definitiva quiso equiparársele (45).

\section{EnRIQUe MARTínez USERos,}

Catedrático de Derecho Administrativo en la Universidad de Murcia.

nada materia, con el fin de instruir a los obligados o deseosos de aprenderla, según que las reglas sean coercitivas o morales o de simple ilustración; y aplicando este principio a la legal proclama el Tribunal Supremo en uso de sus facultades y como ún:ca autoridad al efecto, que merece el concepto de doctrina legal la contenida en las leyes mismas o la declarada por el propio Supremo Tribunal al interpretarlas $\alpha$ aplicarlas en razón a su sentido y fines; y esta declaración ha de tenerse en cuenta para comprender lo que es el recurso extraordinario de apelación, porque sólo a doctrina se contrae...D. Interesante juzgamos lo transcrito, por el alcance extensivo que se da al valor de la doctrina jurisprudencial, no ya er fallos conociendo de los recursos de apelación extraordinaria - supuesto indudable èn el que es la jurisprudencia fuente juridica en Derecho administrativo-, sino en el rango general que en este Considerando se contempla.

(45) Es más l:mitado el ámbito de aplicación de este recurso que el de la casación, pues el primero exige necesariamente no ya la doctrina errónea sino la gravecuad dét daño (scritencia de 8 de fcbrcto de 19x̂) quic se hà de valorar, no en consecuencia a la importancia intrínseca de lo que se discute, sino en razón de la gravedad que resulte de la posible repetic:ón de casos basados en: la doctrina errónea. (Sentencia de 29 de marzo de 1949.) 